\title{
Sensitive Data
}

National Cancer Institute

\section{Source}

National Cancer Institute. Sensitive Data. NCI Thesaurus. Code C142683.

Any information that, in the event of re-identification, would harm a patient in terms of

employability, reputation, insurability, or self-esteem or results in loss of income. (HIPAA) 